\title{
SUSCEPTIBILIDAD DE LA PALOMA SILVESTRE (Columba livia) A UN VIRUS VELOGÉNICO VISCEROTRÓPICO DE LA ENFERMEDAD DE NEWCASTLE EN CONDICIONES EXPERIMENTALES
}

\author{
Fabiola Caballero R. ${ }^{1}$, Mónica Alba C..$^{2,3}$, Eliana Icochea D'A. ${ }^{2}$, \\ Rosa Perales C. ${ }^{4}$ y Raúl Rosadio A. ${ }^{5}$
}

\section{Abstract}

The objective of the study was to asses the susceptibility, pathological effect and serological response of wild pigeons (Columba livia) to Newcastle virus. A total of 28 adult wild pigeons were captured, 14 were inoculated with a velogenic viscerotropic strain of Newcastle virus by oral and nasal route, and the remaining birds were used as a control group. Clinical signs and mortality were recorded. Blood samples were collected for the hemaglutination inhibition technique. Tissue samples from lung and trachea were collected, and cloacal swabs were harvested for virus recovery and histological studies. Birds of the inoculated group showed clinical signs (64\%) and mortality (42.8\%). The clinical signs (sneezes, ruffled plumage, isolation and lethargy) started at day 4 after inoculation. The $43 \%$ of birds showed nervous signs (opisthotonos and tremors of head and neck) and $21 \%$ had diarrhea. In the necropsy was observed a widespread congestion and splenomegaly. The microscopic injuries were edema, gliosis, mononuclear perivascular cuffing in brain and cerebellum, loss of cillia, lymphoid infiltration in trachea, lung congestion, proventricular congestion, lymphocitic infiltration in intestines, and lymphoid depletion in spleen. The inoculated group showed the highest antibody titer (4.9) in the second week. The viral recovery was made upon lung and trachea tissues. It was showed that the specie Columba livia was susceptible to the experimental inoculation with a velogenic strain of Newcastle diasease virus.

Key words: Newcastle disease, avian paramyxovirus, Columba livia, pigeon

\section{Resumen}

El objetivo del presente estudio fue evaluar el grado de susceptibilidad, efecto patológico y respuesta serológica de la paloma silvestre (Columba livia) frente a la inoculación experimental con una cepa de virus velogénico de la enfermedad de Newcastle. Se capturaron 28 aves, donde la mitad se inoculó vía nasal y oral, y la otra mitad se mantuvo como grupo control. Se registró signos clínicos y mortalidad. Se tomaron muestras de sangre para la prueba de inhibición de la hemaglutinación y muestras de tejidos de aves muertas y del grupo control para su análisis histopatológico. Se tomaron muestras de pulmón, tráquea e hisopado de cloaca para la recuperación viral,

\footnotetext{
${ }^{1}$ Práctica privada

${ }^{2}$ Laboratorio de Patología Aviar y Producción Avícola, FMV-UNMSM

${ }^{3}$ E-mail: alba.monica@gmail.com

${ }^{4}$ Laboratorio de Histología, Embriología y Patología Veterinaria, FMV-UNMSM

${ }^{5}$ Laboratorio de Microbiología y Parasitología Veterinaria, FMV-UNMSM
} 
durante seis semanas post inoculación. El $64 \%$ de aves del grupo inoculado presentó signos clínicos y una mortalidad del $42.8 \%$. Se presentaron estornudos a partir del $4^{\circ}$ dia; erizamiento de plumas, aislamiento y letargia a partir del $5^{\circ}$ dia; y opistótonos, tremores de cabeza y cuello a partir del $7^{\circ}$ dia post inoculación. Los hallazgos a la necropsia consistieron en congestión generalizada de órganos y esplenomegalia. Las lesiones microscópicas fueron edema, gliosis, manguito perivascular en cerebro y cerebelo, pérdida de cilios, infiltrado de linfocitos en tráquea, congestión en pulmón y proventrículo, infiltración de linfocitos en intestinos y despoblamiento linfoide en bazo. El grupo inoculado incrementỏ sus títulos de anticuerpos a partir de la $\mathrm{l}^{\text {ro }}$ semana liegando, a su máximo promedio geométrico de título de 4.9 en la segunda semana. Se logró la recuperación viral en muestras de puimón y tráquea durante las tres primeras semanas. Se demostró que las aves de la especie Columba livia usadas en este experimento fueron susceptibles a la inoculación experimental con una cepa velogénica del virus de la enfermedad de Newcastle.

Palabras clave: enfermedad de Newcastle, paramixovirus aviar, Columba livia, paloma

\section{INrropucciós:}

El virus de la enfermedad de Newcastle (VEN) es uno de los patógenos más importantes para todo tipo de aves. Desde la primera vez que fue reportada en 1926 en Indonesia e Inglaterra han ocurrido tres panzootias durante las cuales el virus se diseminó a nivel mundial (Alexander, 2003).

Actualmente viene ocurriendo la cuarta panzootia caracterizada por la presencia de un virus velogénico. En Europa se han presentado brotes en granjas pequeñas, criaderos de palomas, aves de presa y de ornato (Alexander, 2003). Las aves columbiformes afectadas presentaron signos clínicos indeterminados como polidipsia, poliurea, anorexia, diarrea y vómito, seguidos por parálisis de las alas, tremores de cabeza y tortícolis, sin presentar disnea, y con una alta mortalidad en pichones (Gerlach, 1994). En América han ocurrido brotes en granjas de explotación intensiva y de gallos de pelea (Alexander, 2003).

En el Perú los estudios realizados en aves silvestres indican que éstas no so n el reservorio del virus. Hace unos años se realizó un estudio para determinar anticuerpos contra el VEN por la prueba de inhibición de la hemaglutinación (IH) en aves psitácidas en cautiverio del zoológico Patronato del Parque de las Leyendas de Lima, Perú. Alli, el $100 \%$ de las aves muestreadas fueron negativas a la prueba, lo que sugiere que estas aparentemente no estuvieron expuestas al virus (Shimabukuro, 2000). Además, se realizó un estudio en aves silvestres del orden Columbiformes en la provincia de Huaral (donde se venian presentando brotes de la enfermedad de Newcastle en granjas de pollos de carne), obteniéndose el 100\% de las muestras negativas, lo que indicaría que no fueron expuestas al virus, y por lo tanto no constituian el reservorio del virus en la zona (Carrión, 2000).

La enfermedad de Newcastle está presente en el Perú en su forma velogénica (Chang, 1998). Las investigaciones sobre esta enfermedad en aves silvestres se han basado en pruebas serológicas; y por otro lado, existen discrepancias en lo referente al comportamiento clínico de la enfermedad en estas aves, debido a que siendo un pais endémico para el virus de la enfermedad de Newcastle no se ha presentado un brote en dicha especie. Asimismo, se tiene que la paloma Columba livia es una habitante frecuente en las instalaciones y alrededores de las granjas avícolas. Por estas razones se realizó el presente estudio, que tuvo como objetivo evaluar el efecto patológico y la respuesta serológica de la especie Columba 
livia frente a la inoculación con una cepa de virus velogénico de la enfermedad de Newcastle aislado de un brote de campo.

\section{Materiales y Métodos}

\section{Captura, inoculación y toma de muestras}

Se capturaron 28 palomas de vida libre del orden Columbiforme, especie Columba livia, mediante trampas. Se inmovilizaron en forma manual y se alojaron en jaulas preparadas para este fin, dándoles un periodo de adaptación de 2 semanas. La alimentación que recibieron fue principalmente en base a maíz refinado y agua ad libitum con complejo B, para evitar el estrés.

Se formaron 2 grupos de 14 aves cada uno (grupo control y grupo inoculado). Este último fue inoculado vía oral y nasal con una cepa velogénica viscerotrópica del virus de la enfermedad de Newcastle (VVEN) aislada de un brote de campo a una dosis de $50 \mu \mathrm{l}$ con una dosis letal embrionaria media $\mathrm{DLE}_{50} 10^{7} / \mathrm{ml}$ por cada vía. Se colectaron muestras de sangre de la vena braquial (1 $\mathrm{ml} / \mathrm{ave}$ ) el día de la inoculación y semanalmente por 6 semanas.

Se realizó necropsias de las aves muertas y moribundas, registrándose las lesiones macroscópicas. Se colectaron muestras de pulmón, tráquea, cerebro, proventrículo, molleja, intestinos, bazo, e hígado para el análisis histopatológico. Además, se congelaron muestras de pulmón y tráquea e hisopados de cloaca para su inoculación en huevos embrionados para la recuperación viral (Alexander, 1998, 2003; Villegas, 1998).

\section{Signos clínicos}

Se registraron los siguientes signos clínicos tres veces por día y en forma diaria, desde el primer día post inoculación hasta el día de la muerte del ave o hasta finalizar el experimento:
- Depresión, letargia, erizamiento de plumas, anorexia.

- Signos respiratorios: descargas nasales, estornudos y ronqueras.

- Signos digestivos:presencia de diarreas.

- Signos nerviosos: presencia de opistótonos, parálisis, tremores, incoordinación al caminar, caminatas circulares y dificultad de pararse en la percha.

\section{Prueba de inhibición de la hemaglutinación (IH)}

Se utilizó la prueba de IH para la detección de anticuerpos (Alexander, 1998). Como antigeno viral se usó una suspensión de virus vivo vacunal de la enfermedad de Newcastle, cepa La Sota, con pasajes en embrión de pollo y con una concentración de 4 unidades hemoaglutinantes de antígeno.

\section{Resultados}

\section{Signos clínicos}

Las aves del grupo control no presentaron signos clínicos ni mortalidad en la fase experimental. Tres de las 14 aves inoculadas mostraron sintomatología respiratoria, principalmente estornudos a partir del cuarto día post inoculación, y 6 aves adicionales presentaron signos clínicos entre el sexto y noveno día, resultando en un total de $64 \%$ de palomas con signos clínicos (Cuadro 1).

\section{Mortalidad}

Un total de 4 aves murieron en el día 8, 10,14 y 26 post inoculación con signos respiratorios y nerviosos, y 2 aves moribundas fueron sacrificadas el día 9 y 23.

En total, se registró una mortalidad del $42.8 \%$ (6/14). El resto de aves del grupo inoculado (8 palomas) fue sacrificado al finalizar el experimento denotando una condición aparentemente saludable. 
Cuadro 1. Cronología de la presentación de los signos clinicos en 14 palomas silvestres (Columba livia) inoculadas con un virus de la enfermedad de Newcastle

\begin{tabular}{|c|c|c|c|c|c|c|c|c|c|c|c|c|c|c|c|c|c|}
\hline \multirow{2}{*}{$\begin{array}{l}\text { Signos } \\
\text { clínicos }\end{array}$} & \multicolumn{15}{|c|}{ Días post inoculación } & \multicolumn{2}{|c|}{ Total } \\
\hline & $1-3$ & 4 & 5 & 6 & 78 & 9 & 10 & 11 & 12 & 13 & 14 & $15-22$ & 23 & $24-25$ & $26-44^{1}$ & $n$ & $\%$ \\
\hline Depresión & 0 & 0 & 3 & 4 & 43 & 2 & 2 & 2 & 2 & 3 & 2 & 2 & 0 & 0 & 0 & 6 & 42.8 \\
\hline Respiratorios & 0 & 3 & $3^{2}$ & $4^{2}$ & 67 & 7 & 6 & 5 & 4 & 2 & 0 & 0 & 0 & 0 & 0 & 9 & 64,0 \\
\hline Digestivos & 0 & 0 & 0 & 0 & 01 & 2 & 1 & 1 & 1 & 2 & 1 & 1 & 0 & 0 & 0 & 3 & 21.0 \\
\hline Nerviosos & 0 & 0 & 0 & 0 & 22 & 2 & 1 & 1 & 1 & 3 & 2 & 2 & 1 & 1 & 0 & 6 & 42.8 \\
\hline Total & & & & & & & & & & & & & & & & 9 & 64.0 \\
\hline
\end{tabular}

${ }^{2} 2$ de 14 palomas presentaron leve descanga nasal al $5^{\circ}$ y $6^{\circ}$ dia, respectivamente

${ }^{1}$ No se presentaron signos clínicos entre el dia 26 y 44

\section{Prueba de inhibición de la hemaglutinación}

Las muestras de sangre se procesaron mediante la prueba de $\mathrm{IH}$ para determinar el nivel de anticuerpos contra la enfermedad de Newcastle. El grupo control se mantuvo con un promedio geométrico de títulos (PGT) de 2 durante todo el experimento, lo que evidencia que las aves no fueron expuestas al virus de la enfermedad de Newcastle; mientras que el grupo inoculado mostró un incremento en sus títulos a partir de la primera semana de la inoculación ( $\mathrm{PGT}=3.0$ ), llegando a su máximo nivel en la segunda semana ( $\mathrm{PGT}=4.9$ ), descendiendo por completo a la quinta semana (PGT $=2.0)$, como se muestra en la Fig. 1.

\section{Aislamiento viral}

No se logró aislamiento viral a partir de hisopados de cloaca, ni en el grupo control, ni en el inoculado; aunque en este último se presentó mortalidad en los embriones entre las 72 y 144 horas post inoculación, pero sin aglutinación de globulos rojos del liquido alantoideo.

En el grupo control no se logró aislamiento viral a partir de pulmón y tráquea. En el grupo inoculado se observó mortalidad embrionaria a las 72 y 144 horas post inoculación en las muestras tomadas. El fluido alantoideo de 5 embriones que murieron inocu- lados con muestras de pulmón y tráquea obtenidas durante la primera, segunda y tercera semana post inoculación, y el fluido alantoideo de 2 embriones que no murieron produjeron aglutinación positiva de glóbulos rojos, lo que evidenció la presencia del virus (Cuadro 2).

\section{Lesiones macroscópicas}

Los hallazgos de necropsia en las aves muertas y sacrificadas por la enfermedad consistieron principalmente en congestión general en los diferentes órganos.

En las aves necropsiadas durante la primera semana se observó superficie brillosa del cerebro y cerebelo, leve congestión en pulmón, hígado, proventrículo, molleja e intestinos, y moderada esplenornegalia. En el ave necropsiada en la segunda semana se observó baja condición corporal, severa congestión en cerebro, cerebelo e intestinos con contenido oscuro, moderada congestión en pulmones, leve congestión en proventriculo, molleja e higado, y moderada esplenomegalia. En las dos aves de la tercera semana se apreció severa congestión en cerebro y cerebelo con superficie brillante, moderada congestión en pulmones, higado y proventriculo; y en el ave que a su vez presentó diarrea, se observó baja condición corporal, leve congestión en molleja y proventrículo e intestinos severamente congestionados con zonas hemorrágicas y moderada esplenomegalia. 


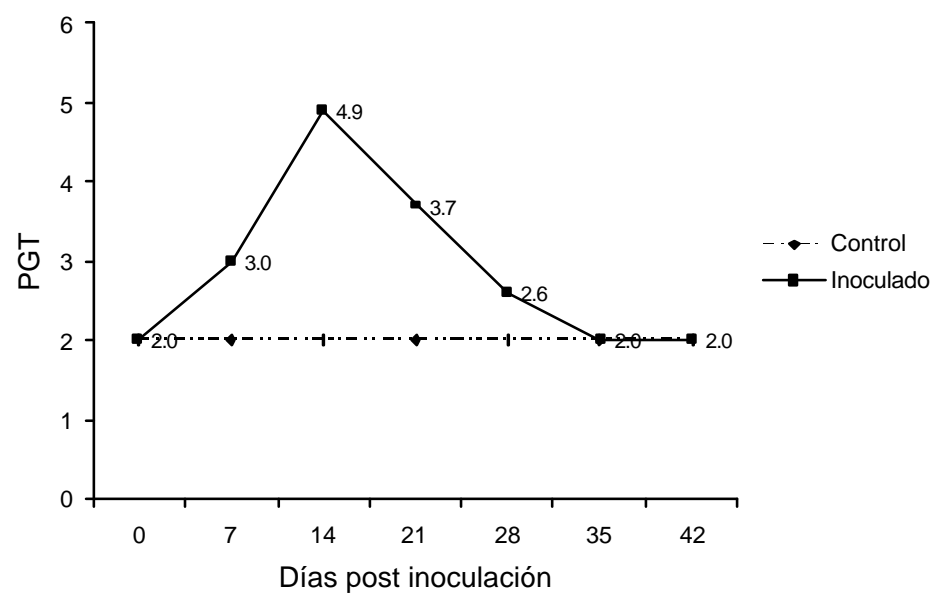

Figura 1. Promedio geométrico de títulos (PGT) de anticuerpos contra el virus de la enfermedad de Newcastle en palomas (Columba livia) que fueron inoculadas con una cepa velogénica viscerotrópica

Cuadro 2. Mortalidad de embriones y resultados de la presencia de virus de la enfermedad de Newcastle mediante la prueba de inhibición de la hemaglutinación en embriones inoculados con muestras de pulmón y tráquea tomadas de palomas Columba livia inoculadas con una cepa velogénica viscerotrópica del virus de la enfermedad de Newcastle

\begin{tabular}{|c|c|c|c|c|c|c|c|}
\hline \multirow{2}{*}{$\begin{array}{c}\text { Días } \\
\text { post inoculación }\end{array}$} & \multicolumn{6}{|c|}{ Ocurrencia de mortalidad de embriones ${ }^{1}$} & \multirow{2}{*}{$\begin{array}{l}\text { Presencia de virus } \\
\text { (hemaglutinación) }\end{array}$} \\
\hline & $24 \mathrm{~h}$ & $48 \mathrm{~h}$ & $72 \mathrm{~h}$ & $96 h$ & $120 \mathrm{~h}$ & $144 \mathrm{~h}$ & \\
\hline 8 & & & 1 & & & & $1 / 5$ \\
\hline 9 & & & 1 & 2 & & & $(-)$ \\
\hline 10 & & & & & & & $(-)$ \\
\hline 14 & & & 1 & 2 & 1 & & $5 / 5$ \\
\hline 23 & & & & & & 1 & $2 / 5+/-$ \\
\hline 26 & & & & & & & $(-)$ \\
\hline 44 & & & & & & & $(-)$ \\
\hline
\end{tabular}

${ }^{1}$ Se utilizaron 5 embriones por grupo

\section{Histopatología}

No se observó lesiones histopatológicas relevantes en los órganos de las aves del grupo control mientras, que en las muestras de las aves del grupo inoculado, que presentaron signos nerviosos y respiratorios, se observaron las lesiones histopatológicas descritas en el Cuadro 3.

\section{Discusión}

La especie Columba livia mostró menor susceptibilidad (42\% de mortalidad) a la enfermedad de Newcastle, en comparación a los pollos de carne y pollitas de postura, donde la literatura reporta mortalidades del 60 a 100\% (Alba et al., 1999; Icochea et al., 
Cuadro 3. Lesiones histopatológicas observadas en las tres primeras semanas postinoculación en órganos de palomas (Columba livia) inoculadas con una cepa velogénica del virus de la enfermedad de Newcastle

\begin{tabular}{|c|c|}
\hline Órgano & Lesión histopatológica \\
\hline Cerebro & $\begin{array}{l}\text { Leve congestión, edema perivascular y perineuronal, vacuolización y } \\
\text { degeneración neuronal, gliosis, satelitosis, manguito peri-vascular de } \\
\text { mononucleares, endoteliosis. }\end{array}$ \\
\hline Cerebelo & $\begin{array}{l}\text { Edema en capa granular, deslineamiento, degeneración y vacuoli- } \\
\text { zación de células de Purkinje. }\end{array}$ \\
\hline Tráquea & $\begin{array}{l}\text { Edema en submucosa, infiltrado de linfocitos en mucosa, dilatación } \\
\text { y/o vacuolización glandular, exudado transepitelial, acortamiento de } \\
\text { cilios y exfoliación. }\end{array}$ \\
\hline Pulmón & Moderada congestión. \\
\hline Proventrículo & Leve congestión. \\
\hline Molleja & Aparentemente normal. \\
\hline Intestinos & $\begin{array}{l}\text { Congestión e hiperplasia de glándulas de Lieberkhüm; edema de } \\
\text { células epiteliales y espacio coriónico en etapas avanzadas. }\end{array}$ \\
\hline Hígado & Congestion. \\
\hline Bazo & $\begin{array}{l}\text { Moderada congestión, despoblamiento linfoide, lisis de linfocitos y } \\
\text { edema intrafolicular. }\end{array}$ \\
\hline
\end{tabular}

1999). Sin embargo, Erickson et al. (1977, 1979) reportaron una mortalidad de $55 \%$ en conuros y del $23 \%$ en palomas. Simultáneamente, Shivaprasad (1991) y Shivaprasad et al. (1999) reportaron mortalidades similares en brotes en palomas en cautiverio.

Las palomas presentaron signos clínicos respiratorios y digestivos consistentes en descarga nasal, estornudos y diarrea a partir del cuarto día post inoculación similares a lo descrito por Erickson et al. (1977) en aves silvestres nebulizadas con la cepa COPIVVVEN.

El tipo de signos clínicos obsèrvados en el presente estudio fueron similares a los ob- servados en un brote producido por una cepa lentogénica en faisanes y palomas en cautiverio (Shivaprasad et al., 1999). En los brotes en palomas y aves exóticas captivas que ocurrieron hace muchos años en el área tropical de México, las aves mostraron un incremento de la frecuencia respiratoria, mandibulas separadas, plumas adheridas alrededor de las fosas nasales como consecuencia de la descarga nasal, incoordinación $n_{\text {asi }}$ como opistótonos y postración, que precedian la muerte (Estudillo, 1972). Estos signos respiratorios fueron más graves que los observados en este experimento, pero los signos nerviosos fueron similares (tremores, opistótonos $y$ torticolis) a aquellos que se presentaron al tercer día de la inoculación. 
Similar sintomatología nerviosa fue descrita por Erickson et al. (1979) cuando inocularon palomas jóvenes y adultas de competencia con la cepa Fontana, vía ocular, y en aves silvestres nebulizadas con la cepa COPI-VVNDV; y por Shivaprasad (1991) en un brote producido por un APMV-1 en palomas mensajeras no vacunadas. En ambos casos no se presentaron signos respiratorios. Los signos clínicos observados varían independientemente de si se trata de un brote natural o de una inoculación experimental, pues probablemente estas variaciones se deban a condiciones inherentes al virus, tipo de cepa viral, especie de ave afectada, ruta de infección, estado sanitario del individuo y exposiciones previas al virus.

Los niveles de anticuerpos alcanzaron su pico en la segunda semana, siendo similares a los reportados por Shivaprasad (1991) en un brote en palomas en cautiverio causado por una cepa lentogénica; pero fueron mucho menores a los obtenidos por Erickson et al. (1979) con la cepa La Fontana (PGT= 8.0) y la cepa Largo $(\mathrm{PGT}=32.0)$ en palomas mensajeras jóvenes y adultas.

La recuperación viral sólo se pudo hacer de muestras de pulmón y tráquea pero no de hisopado de cloaca, probablemente debido a la diseminación y persistencia del virus en la especie inoculada.

Las lesiones macroscópicas encontradas en las aves del grupo inoculado que murieron con signos de la enfermedad de Newcastle fueron similares a las reportadas por Shivaprasad et al. (1999) en palomas exóticas y faisanes, pero menos severas a las halladas por Erickson et al. (1979) en palomas de competencia, y por Erickson et al. (1977 en aves silvestres.

Las lesiones histopatológicas observadas en el sistema nervioso fueron similares a las observadas por Shivaprasad (1991) causadas por una infección con APMV-1 en palomas mensajeras no vacunadas; y similares a las observadas por Kommers et al. (2001) en pollos inoculados con cepas APMV-1 aisladas de palomas, aunque en este caso se reportó lesiones más severas en hígado y proventrículo.

\section{Conclusiones}

- La especie Columba livia mostró ser susceptible a la enfermedad de Newcastle por inoculación experimental, debido a que desarrolló signos clínicos respiratorios, digestivos, nerviosos y mortalidad en el $43 \%$ de las aves.

- El virus se logró recuperar en huevos embrionados a partir de muestras de pulmón y tráquea, pero no de muestras de hisopados de cloaca.

- El desarrollo de niveles detectables de anticuerpos en estas aves demuestran que poseen un sistema inmune activo, el cual influye en la protección y recuperación de las aves que presentaron signos respiratorios.

\section{Literatura Citada}

1. Alba, M.; E. Icochea; A. Silva; O. Vidal. 1999. Protección vacunal-oleosa en pollos broilers contra una cepa viscerotrópica velogénica del virus de la enfermedad de Newcastle. En: XVI Congreso Latinoamericano de Avicultura. Lima, Perú. p 270.

2. Alexander, D.J. 1998. Newcastle disease and other avian paramyxoviruses. En: A laboratory manual for the isolation and identification of avian pathogens. Swayne, D.; J.R. Glisson; M.W. Jackwood; J.E. Pearson; W.M. Reed (eds). $4^{\text {th }}$ ed. p 156163. The American Association of Avian Pathologists. USA.

3. Alexander, D.J. 2003. Newcastle disease and other avian Paramyxo viridae infections. En: Diseases of Poultry. Saif, Y.M. $11^{\text {th }}$ ed. p 63-87. Iowa State University Press. USA. 
4. Carrión, A. 2000. Prevalencia de anticuerpos contra el virus de la enfermedad de Newcastle en aves silvestres del orden columbiforme en Baños de Boza, distrito de Okayama, provincia de Huaral. Tesis de Médico Veterinario. Facultad de Medicina Veterinaria, Univ. Nacional Mayor de San Marcos. Lima. 33 p.

5. Chang, P. 1998. Detección de la prevalencia de anticuerpos contra el virus de la enfermedad de Newcastle en aves silvestres paseriformes y columbiformes en la provincia de Chancay. Tesis de Médico Veterinario. Facultad de Medicina Veterinaria, Univ. Nacional Mayor de San Marcos, Lima 23 p.

6. Erickson, GA.; B. Brugh; C.W. Beard. 1977. Viscerotropic velogenic Newcastle disease virus and pet birds of six species. I. Clinical and serology responses, and viral excretion. Avian Disease 21: 642-654.

7. Erickson, GA:, B. Brugh; C.W. Beard. 1979. Viscerotropic velogenic Newcastle disease in pigeons: clinical disease and immunization. Avian Disease 24: 257-267.

8. Estudillo J. 1972. A Newcastle disease outbreak in captive exotic birds. Proceeding of the Western Poultry Disease Conference 21: 70.

9. Gerlach, H. 1994. Disease etiologies: Viruses. En: Avian Medicine: Principles and aplication. Ritchie, B.W; G.J. Harrison (eds). p 920-929. Wingers Publishing. Florida.
10. Icochea, E; M. Ramírez; M. Alba; $O$. Vidal; M. Ticona. 1999. Protección vacunal mixta oleosa-viva en pollitas de postura contra una cepa viscerotrópica velogénica del virus de la enfermedad de Newcastle. En:XVICongreso Latinoamericano de Avicultura. Lima, Perú. p 270.

11. Kommers, GD.; D.J. King; B.S. Seal; C.C. Brown. 2001. Virulence of pigeonorigen Newcastle disease virus isolates for domestic chickens. Avian Disease 45: 906-921.

12. Shimabukuro, C.I. 2000. Determinación de anticuerpos contra el virus de la enfermedad de newcastle en psitácidas en cautiverio en el Parque de las Leyendas. Tesis de Médico Veterinario. Facultad de Medicina Veterinaria, Univ. Nacional Mayor de San Marcos. Lima. 26 p.

13. Shivaprasad, H. 1991. Paramyxovirus1 infection in the domestic pigeon. Proceeding of the Western Poultry Disease Conference 40: 256.

14. Shivaprasad, H; D. Rupiper; P.R. Woolcock. 1999. An outbreak of Newcastle disease in exotic pheasants and doves. Proceeding of the Western Poultry Disease Conference 48: 43.

15. Villegas, R. 1998. Avian Virus Diseases, Laboratory Manual. p 39-43. College of Veterinary Medicine. The University of Georgia, Atlanta. 